\title{
RESEARCH ETHICS IN EDUCATION
}

KEY WORDS: Research, Ethical Issues, Education

\section{Mr.vinod Misra \\ Dr. Ritu Tyagi* \\ Lecturer Institute For Education \& Technical Science IET College Abupur \\ Principal Institute For Education \& Technical Science IET College Abupur *Corresponding Author}

Ethics refers to rules of conduct for carrying out research. It includes the moral principles that govern the behaviour of a person or conducting an activity. Ethics means a set of principle that determines the right and acceptable conduct. Ethical issues involving research participants include collecting information, seeking consent, providing incentives, seeking sensitive formation, possibility of harm, maintaining confidentiality, anonymity, privacy, dignity. Ethical issues involving researcher include avoiding bias, incorrect reporting, inappropriate use of information, inappropriate research methodology. Unethical practices include breaching confidentiality, causing harm to individuals, using information inappropriately, introducing bias. The paper focuses on the research ethics in education.

\section{INTRODUCTION}

Ethics refers to rules of conduct for carrying out research. It includes the moral principles that govern the behaviour of a person or conducting an activity. Ethics means a set of principle that determines the right and acceptable conduct. Ethical issues involving research participants include collecting information, seeking consent, providing incentives, seeking sensitive formation, possibility of harm, maintaining confidentiality, anonymity, privacy, dignity. Ethical issues involving researcher include avoiding bias, incorrect reporting, inappropriate use of information, inappropriate research methodology. Unethical practices include breaching confidentiality, causing harm to individuals, using information inappropriately, introducing bias. Ethics refers to code of conduct that governs how people treat each other and the way people act or behave. It involves the understanding and examining the moral life or the right and wrong of human conduct. Research ethics provide guidelines to people for conducting research keeping in mind the ethical standards. Ethics should be followed from the selection of the problem till publication of the research findings. The paper focuses on the research ethics in education.

\section{SAMPLE SIZE}

Sample size must be justified to provide valid and generalized results.

\section{OBJECTIVITY}

Bias in any form should be avoided in research design, data analysis and peer review. Never recommend anyone you already know for peer review or with whom you have already worked with.

\section{CAREFULNESS}

Review the results of your research carefully and critically to ensure that the results are credible. Avoid careless mistakes. Always keep record of your research. If researcher is not careful his study can put him in a situation involving risk. Negligence and careless errors should be avoided.

\section{INTEGRITY}

Any breach of integrity during research will seriously weaken or invalidates the research.

\section{DATA COLLECTION}

Methods of data collection should be described clearly to avoid ethical problems. The researcher should possess the necessary skills for collecting data. Data collection through participant observation can be used if any other method is not available.

\section{HONESTY}

Researcher should ensure that there is honesty and transparency at every stage of research. Methods of data collection, analysis of data, data interpretation and other aspects of research should be honestly reported.

\section{DATA SECURITY}

With the advancement in science and technology it becomes difficult to protect data. Measures to ensure data privacy should be implemented.

\section{CONFIDENTIALITY}

Confidentiality of the participants must be maintained and anonymity respected. The participants should know the objectives and the purpose of the research and what is going to happen with the data collected. The researcher should ensure the participant that his data will be kept confidential and should not be shared with anyone. There is limitation of confidentiality also and this happens when the participant tells the researcher that there is some illegal activity and this can cause harm to the participant. Confidentiality can be breached when the researcher is conducting interviews or taking case studies of only few participants and there is greater probability that these participants could be easily identifiable.

\section{INFORIED CONSENT}

The researcher should not put the participants in a state of discomfort or psychological distress. The participants should not be put in risk of harm. Harm can be physical or psychological. He should take informal consent from the participants before conducting the research. The participants should have the power of choice and they can decline their participation voluntarily. He should protect the confidentiality of the participants.

\section{WRITE UP AND PUBLICATION}

Research misconduct involves fabrication, falsification and plagiarism in reporting the results of research. These are considered unethical practices in research.

Falsification involves manipulating research results, changing and manipulating data and not accurately represent the findings of research.

Plagiarism is inappropriate use of other person's idea, results without giving them credit. The use of any other person's work or idea or data must be cited or given credit and must be mentioned in the references.

\section{VULNERABLE SUBJECTS}

People with disabilities, mentally challenged, learning 
disabled, infants, older men and women, pregnant ladies are vulnerable subjects.

\section{OPENNESS}

After completing research if you want to publish the research findings or any tool that you have developed be open to share it with others so that it will help in further advancement of knowledge. Be prepared for criticism and new ideas.

\section{LEGALITY}

Always be aware and conform to the laws that govern your research. Obey institutional and government laws and policies.

\section{PROTECTION}

It is the task of the researcher to protect the participants in investigation.

\section{HUMAN SUBJECTS}

To address this issue most of the organizations have developed Institutional Review Board (IRB). The ensure that the ethical practices are utilized and ensure safety of human subjects also.

\section{RESPECT HUMAN DIGNITY}

Give respect to colleagues. Treat them fairly and maintain human dignity. Avoid any form of discrimination in the form of sex, caste, colour, creed or race.

\section{CONCLUSION}

Ethics refers to rules of conduct for carrying out research. It includes the moral principles that govern the behaviour of a person or conducting an activity. Ethics means a set of principle that determines the right and acceptable conduct. Ethical issues involving research participants include honesty, integrity, collecting information, informed consent, seeking sensitive formation, possibility of harm, maintaining confidentiality, anonymity, privacy, legality, protection and respect human dignity.

\section{REFERENCES}

1. University of Queensland. (2002). Research Ethics Policy. Retrieved 2nd Oct 2006, from http://www.uq.edu.au/hupp/index.html

2. Resnik, D.B. (2015).What is Ethics in Research \& Why is it Important?

3. National Institue of Environmental Health Sciences. Retrieved from https://www.niehs.nih.gov/research/resources/bioethics/whatis. 